\title{
A Alteridade no Discurso da Reforma Psiquiátrica Brasileira face à Ética Radical de Lévinas
}

\author{
MARIA GABRIELA CURUBETO GODOY " \\ MARIA LÚCIA MAGALHÃES BOSI •
}

Este artigo trata das premissas éticas da Reforma Psiquiátrica, mais especificamente, da desinstitucionalização enquanto desconstrução, a partir do pensamento de Emmanuel Lévinas, e a concepção de alteridade postulada a partir da proposta de uma ética radical. O resgate dos pressupostos éticos da Reforma Psiquiátrica, considerados sob novos enfoques teóricos, pode contribuir para desvelar e compreender os diversos caminhos que esse processo vem tomando com a diversidade de práticas em construção e a disseminação de serviços substitutivos em saúde mental.

Palavras-chave: Reforma Psiquiátrica; alteridade; saúde mental.

Recebido em: 23/11/2006.

Aprovado em: 19/04/2007. 


\section{Introdução}

Este ensaio discorre sobre as concepções de alteridade presentes na conformação do discurso da Reforma Psiquiátrica, a partir de distintas compreensões acerca da desinstitucionalização presentes na literatura de referência nesse domínio, no intuito de esboçar uma análise em relação à proposta de alteridade consoante as proposições da ética radical em Emannuel Lévinas. Para além de um interesse particular acerca do tema, motiva-nos empreender uma reflexão em relação à observação de lacunas sobre essa discussão na literatura especializada a respeito do objeto, no campo da Saúde.

É na interface dos campos da Saúde Coletiva e da Saúde Mental, caracterizados por uma grande diversidade discursiva e práticas a ela associadas, que se insere o processo de Reforma Psiquiátrica. Considerado um processo social complexo, a partir do qual se desencadearam modificações em diversas dimensões, tal movimento vem tendo como desfecho a produção de um novo olhar sobre a loucura e suas abordagens.

No Brasil, ao longo das últimas décadas, outro processo com implicações importantes - o movimento de Reforma Sanitária - tem convergido com o da Reforma Psiquiátrica, constituindo novas práticas no campo da Saúde Mental desenvolvidas dentro do Sistema Único de Saúde (SUS). Os princípios do SUS - universalidade, eqüidade e integralidade - que constituem premissas éticas fundamentais dessa proposta, são compartilhados pelo processo da Reforma Psiquiátrica, embora esta apresente também determinadas premissas específicas, dentre elas a desinstitucionalização, sobre a qual iremos nos debruçar.

As implicações das diferentes concepções de desinstitucionalização no campo da Saúde Mental têm contribuído para situar a discussão no âmbito dos direitos humanos, ressaltando a dimensão ética dos pressupostos que norteiam diferentes perspectivas de Reforma Psiquiátrica. Neste sentido, realizar uma leitura dos pressupostos da Reforma Psiquiátrica transversalizada pela ética, tal como concebida por Lévinas, pode subsidiar a discussão sobre a alteridade impressa na relação com a loucura, possibilitando a construção de diálogos entre a obra desse autor e o campo da Saúde.

Para tanto, iniciaremos com uma breve exposição dos pressupostos do processo de Reforma Psiquiátrica no Brasil, e de algumas de suas correntes de influência, de maneira a esboçar uma caracterização sobre o tratamento dado à questão da alteridade nessa área. Na sequiência, apresentaremos algumas 
A Alteridade no Discurso da Reforma Psiquiátrica Brasileira...

categorias fundamentais da ética "levinasiana", a fim de subsidiar a discussão sobre a alteridade vislumbrada em cada uma dessas perspectivas.

\section{Algumas compreensões sobre a desinstitucionalização}

Podemos caracterizar a Reforma Psiquiátrica enquanto um processo social complexo, no qual estão presentes diversas dimensões: a teóricoconceitual; a jurídico-política, a técnico-assistencial e a sociocultural.

A dimensão teórico-conceitual trata da desinstitucionalização, termo polissêmico no qual nos deteremos adiante. A jurídico-política aborda os direitos essenciais dos(as) portadores de transtornos mentais, afetados pela perda de direitos, sobretudo, de direitos civis (relativos à liberdade individual de ir e vir, comunicar-se, assumir responsabilidades, portar seus pertences, dentre outros), sociais (relacionados à distribuição de bens) e políticos. Essa dimensão trata, também, do arcabouço jurídico-institucional no campo da Saúde, que referenda a organização do modelo de atenção em saúde mental.

Já a dimensão técnico-assistencial inclui a discussão sobre questões como "a organização de novos modelos assistenciais", dos quais fazem parte a constituição de uma "rede territorial em saúde mental" com a "atenção centrada no território", a "interdisciplinaridade", a "intersetorialidade" e o "novo papel dos técnicos".

Por fim, a dimensão sociocultural, conforme veremos, pode ser incluída numa das compreensões sobre a desinstitucionalização, pelo fato de propor o deslocamento da loucura dos espaços "psi" (médicos e psicológicos) para os diversos espaços do meio social, e por objetivar a transformação do imaginário social em torno da loucura/doença mental construído e sustentado pelo saber psiquiátrico ao longo dos últimos dois séculos.

Alguns aspectos relevantes dessas dimensões fundamentam concepções inovadoras sugeridas aos novos dispositivos de saúde mental, pautadas pelas seguintes características:

- multidimensionalidade e complexidade da atenção às pessoas com transtornos mentais graves;

- construção complexa do projeto terapêutico na perspectiva da reabilitação psicossocial, visando à produção de autonomia, à 
construção de cidadania, à inclusão social e à contratualidade, ${ }^{1}$ estimulando a inserção no trabalho no contexto da economia solidária, superando, assim, o referencial do "trabalho protegido";

- valorização das atividades que tecem a vida cotidiana;

- atuação no território, fomentando o fortalecimento de redes de apoio.

Tais características partem de pressupostos da dimensão teóricoconceitual, relacionada à desinstitucionalização da loucura, que também é considerada a principal premissa ética da Reforma Psiquiátrica, embora apresente diversas compreensões, podendo ser associada: à desospitalização, à dessassistência, ou à "desconstrução".

Podemos reconhecer que a desinstitucionalização enquanto desospitalização, incorporada e difundida pela Organização Mundial da Saúde (OMS), emerge nos Estados Unidos, em decorrência do preventivismo e sua influência no Plano de Saúde Mental do Governo Kennedy, tendo como princípios fundamentais: a) a prevenção de internações em instituições psiquiátricas; b) o retorno para a comunidade de todos os pacientes institucionalizados; e c) o estabelecimento e manutenção de sistemas de suporte comunitário.

Apesar de representar certos avanços, a proposta é criticada por se limitar a transformações mais ou menos superficiais, administrativas, organizativas e modernizantes do aparato prático-discursivo da Psiquiatria, sem superar o paradigma fundante, nem tampouco questionar o arcabouço teórico a partir do qual a Psiquiatria tradicional apreende o fenômeno da loucura. Segundo Amarante (1996, p. 17), esta proposta "reporta à Psiquiatria um campo epistêmico que delineia o 'ideal da saúde mental' [...] e edifica o ideal da ausência das doenças mentais no meio social".

A desinstitucionalização enquanto desassistência é uma compreensão disseminada entre segmentos que se opõem à "desinstitucionalização", seja por resistir a qualquer idéia que represente a ampliação dos direitos e igualdade de setores considerados minoritários, seja por ter interesses específicos nas formas tradicionais de organização da Psiquiatria. O discurso apregoado afirma que os pacientes serão desamparados, enviados para fora do hospital sem a implantação de uma infra-estrutura comunitária para cuidar dos mesmos e de suas famílias. No caso brasileiro, 
A Alteridade no Discurso da Reforma Psiquiátrica Brasileira...

setores da Psiquiatria tradicionalmente corporativos e conservadores aliados aos interesses econômicos de exploração da loucura ("empresários da loucura") representam os principais defensores dessa concepção de desinstitucionalização.

A desintitucionalização enquanto desconstrução pressupõe, segundo Amarante (1998, p. 49), "uma ruptura radical com o saber/prática psiquiátrica [...] operada tanto em relação à Psiquiatria tradicional (o dispositivo da alienação), quanto em relação à nova psiquiatria [preventivista] (o dispositivo de saúde mental)". Trata-se de um projeto de desconstrução de saberes/práticas/discursos comprometidos com uma objetivação da loucura e sua redução à doença.

\section{Breve histórico da Psiquiatria e a configuração da desinstitucionalização enquanto desconstrução}

A "Psiquiatria tradicional", com suas funções arcaicas de controle social, coação e segregação, considera o louco um "alienado", que etimologicamente significa "forasteiro", pessoa "alienada" de sua razão, demarcando a construção da loucura como des-razão.

Esse processo, ocorrido no que Foucault (1987) denomina "idade clássica", período entre a época de Descartes e as revoluções burguesas, opera uma profunda cisão entre razão e des-razão, no processo e ascensão do racionalismo cartesiano, fundante da razão metódica e das "boas maneiras de pensar", que excluíam o enlouquecimento. A loucura, antes enquadrada em dimensões mágico-religiosas, torna-se, então, objeto de uma disciplina científica específica: a Psiquiatria, passando a ser reduzida à doença, passível, portanto, de intervenção médica. Assim, a loucura como "alienação da razão" pode justificar, entre outras medidas, práticas de confinamento nos manicômios, como forma de tratamento e segregação propagadas ao longo dos últimos séculos.

Entretanto, as práticas de confinamento, geradoras de uma série de dispositivos disciplinadores, antecedem a criação dos manicômios, tendo seu marco no movimento da Grande Internação, no século XVIII, na Europa, quando uma nova ordem econômica e social impunha medidas de saneamento das cidades e a entronização do trabalho como valor inquestionável. As pessoas que não se adequavam à nova ideologia, predispostas ao ócio, ao descontrole das paixões, que infestavam as cidades, foram confinadas em asilos, onde se aglomeravam prostitutas, órfãos abandonados, mendigos, pessoas acometidas de doenças venéreas, andarilhos, vagabundos e loucos. 
Nesse movimento, inicialmente de segregação geral de todos os outros, ou seja, aqueles desajustados às normas da nova ordem social, e posteriormente de enclausuramento específico da loucura nos manicômios, o princípio de reclusão dos loucos, imperativo jurídico-legal da Grande Internação, transmutou-se, segundo Amarante (1996, p. 113) no "princípio do isolamento, imperativo médico para a loucura, tornada doença mental".

O isolamento - reclusão imposta - é o instrumento mais marcante da Psiquiatria, dada a função social que o acompanha, com as mudanças no modo cultural de lidar com a loucura, na construção social do "estigma", radicalizado pela intervenção psiquiátrica. Sobre o louco é exercida uma ação de violência, de múltiplas segregações: da reclusão social ao abandono nu e imundo no pátio do manicômio, construindo-se a concepção de louco enquanto um ser perigoso, nefasto, incapaz, um "não-ser", legitimando-se a condição de "não-cidadão", "não-sujeito".

O bizarro, excêntrico, estranho e diferente enquadra-se, assim, como "doença" de caráter moral, excluída do convívio social, sendo submetida ao tratamento moral, através da tutela, das medidas disciplinadoras, do controle da sexualidade, da vigilância estrita e da ocupação do tempo livre em atividades "produtivas".

A "nova Psiquiatria" é representada pelo surgimento da Psiquiatria preventiva e comunitária surgida nos EUA, em que, como já dissemos, a desinstitucionalização é compreendida enquanto desospitalização, processo que toma um sentido mais instrumental, relacionado à redução de custos da assistência para os cofres públicos. No entanto, experiências baseadas nessa perspectiva não se têm mostrado menos onerosas, além de, paradoxalmente, a rede de serviços intermediários ter servido mais para aumentar a demanda hospitalar do que efetivamente para desativar os manicômios.

A tendência da desinstitucionalização como desconstrução identificase com a trajetória prático-teórica desenvolvida por Franco Basaglia, caracterizada por um caráter fortemente político de suas idéias e propostas, por sua crítica vigorosa ao saber psiquiátrico, e pelo questionamento da função social cumprida pelos técnicos e pela tecnociência.

Essa concepção de desinstitucionalização, que serviu de inspiração ao movimento de Reforma Psiquiátrica brasileira, pretende, então, desconstruir a exclusão e a lógica manicomial concreta e simbólica que pauta não apenas os 
dispositivos psiquiátricos, mas atravessa também as relações sociais e culturais com a loucura. Essas questões nos remetem ao conceito de cidadania dos loucos, não apenas pela ampliação dos seus direitos sociais, civis e políticos, ou da idéia de cidadania como valor universal, admitindo sua extensão a todo o tecido social, mas trata, sobretudo, de ampliar e diversificar:

O próprio conceito de cidadania, no sentido de admitir a pluralidade de sujeitos, com suas diversidades e diferenças num mesmo patamar de sociabilidade. Trata-se, ainda, não de deixar o louco viver a sua loucura, porém de, em um novo contexto de cidadania, dar-lhe o real direito ao cuidado. Não de ser excluído, violentado, discriminado, mas de receber ajuda em seu sofrimento, em sua positividade e em sua possibilidade de ser sujeito. Enfim, trata-se de trabalhar efetivamente para que ele seja um sujeito de desejos e projetos. (AMARANTE, 1996, p. 115).

\section{A alteridade no pensamento de Emmanuel Lévinas}

O pensamento de Lévinas questiona o primado da ontologia, postulando a anterioridade da ética como filosofia primeira, entendida como "responsabilidade pelo outro" (LÉVINAS, 2005). Esse Outro, pensado a partir de uma dimensão eminentemente ética, origina-se em um modo diferente de pensar, advindo da língua hebraica e alheio à "cosmovisão helenizante" (COSTA, 2000).

Lévinas constrói sua trajetória de pensamento traçando uma crítica ao conceito de ser, a partir de dois sentidos do des-intér-essément: o primeiro e mais comum, gratuidade da relação, cujo móvel não é o interesse; o segundo e mais radical, deixar de conceber a relação do espaço delimitado pela ontologia.

A dificuldade gerada pela multiplicidade de significados que uma só categoria comporta no pensamento levinasiano é apontada por Freire (2002, p. 65-66), ao referir o que Haar considera:

Não parece que o Outro, conforme Lévinas, possa receber uma acepção unívoca [...] o Outro designa com efeito simultaneamente: uma universalidade abstrata, Outrem, concebido como "o absolutamente Outro"; as dimensões pré-reflexivas ou não-representáveis da subjetividade; a passividade, o Infinito, o "Estrangeiro" que ora é o primeiro vindo, um desconhecido, ora o próximo, tal e qual eu o conheço; e, enfim, a particularidade do Rosto onde um outro 
inteiramente singular se apresenta na proximidade de uma face a face que é ao mesmo tempo "altura", distância intransponível.

Para Lévinas, a relação com o Outro é face a face, anterior a toda anterioridade e desprovida de toda mediação, de todo intercâmbio, de toda reciprocidade. Segundo o próprio Lévinas (1963, p. 144):

A relação com o outro não poderia ser pensada como um encadeamento com um outro eu, nem como a compreensão do outro, do qual faria desaparecer a alteridade, nem como comunhão com ele em torno de algum terceiro termo. O "outro" que não é o "eu” é "outro diferente", desconhecido, não-familiar, estranho, em uma posição intersubjetiva assimétrica: $\mathrm{O}$ outro, enquanto outro, não é somente um alter-ego. Ele é o que eu não sou: ele é o débil, enquanto eu sou forte; é o pobre, é a viúva e o órfão. [...] Ou então é o estrangeiro, o inimigo, o poderoso. [...] O espaço intersubjetivo é inicialmente assimétrico.

O Outro é exterioridade, uma alteridade sempre outra, que não pode ser absorvida, reduzida, totalizada, interiorizada, representada pelo "mesmo". O Outro é o que excede e vai além do "mesmo", que remete para o Infinito. O Outro incita o mim-mesmo à "responsabilidade", que é o cerne da ética levinasiana. A "responsabilidade" pelo Outro éilimitada, absoluta e ultrapassa a própria liberdade do mim-mesmo. Para essa responsabilidade absoluta não interessa a contrapartida do outro - nesse sentido, a relação é desinteressada.

A relação com o Outro é desejo. Não um desejo de satisfação das próprias necessidades, pois o que caracteriza o mim-mesmo é o estar farto de saciedade do mundo. É o desejo do absolutamente Outro, para além dos sentidos ou das satisfações. "Desejo sem satisfação que tende, exatamente, para o afastamento, para a alteridade e para a exterioridade do Outro" (LÉVINAS, 1963, p. 58-59).

Partindo do que nos instiga a proposta ética de Lévinas, na sequiência, passaremos à análise das possibilidades de interlocução do Outro, presentes no projeto de desinstitucionalização, considerado o cerne ético das propostas de reforma psiquiátrica, face à alteridade tal como concebida por Lévinas. 
A Alteridade no Discurso da Reforma Psiquiátrica Brasileira...

\section{A alteridade e a loucura}

Partimos do pressuposto de que a dimensão ética presente na proposta de desintitucionalização como desconstrução apresenta concepções de alteridade que se aproximam de algumas idéias de Lévinas. O discurso pela não-exclusão admite a abertura para o Outro impresso na loucura, a partir da consideração de sua diferença, que não pode ser suprimida. A busca de um lugar, a partir do não-lugar em que o "Outro louco" foi colocado, remete para a possibilidade de constituição da subjetividade do mim-mesmo, a partir da alteridade, incitando-o à responsabilidade. Entretanto, a proposta de Lévinas expressa sua radicalidade ao conceber a antecedência do Outro sobre o mimmesmo, o que implicaria a necessidade de aprofundar e reconfigurar a relação entre subjetividade/alteridade na perspectiva dessa proposta.

A loucura representa o Outro, estranho, não-familiar, que se apresenta ao mim-mesmo na sua interioridade, e se projeta e exterioriza no Outro louco, rejeitado, segregado, abandonado. A inclusão da loucura significa não apenas criar um lugar para o não-lugar do Outro fora de mim, mas também encontrar um lugar para o Outro interior ao mim-mesmo. Neste sentido, manter a alteridade implicaria não absorver ou reduzir a diferença, sob o risco de imprimir a "mesmidade" à alteridade.

Uma presença de destaque no discurso da Reforma Psiquiátrica é a figura do terceiro, através da justiça. Esta, segundo Lévinas, pressupõe igualdade, distanciando-se da assimetria característica da relação intersubjetiva com o Outro, que excede o mim-mesmo. Neste sentido, a justiça, que o mim-mesmo cobra não deve ser para si, mas para o Outro. A justiça representada pela proposta de ampliação da cidadania, de não-exclusão, de construção de um lugar, retirando-o do não lugar, coloca a possibilidade de reconstrução da subjetividade violentada do "Outro louco", aproxima-se da cobrança de justiça não para si, mas para esse Outro.

Entretanto, a radicalidade da proposta de Lévinas, vai além de incluir o Outro, pois ele excede o mim-mesmo, remetendo-o ao Infinito. Conclama à responsabilidade absoluta e ilimitada pelo Outro, aprofundando-se em dimensões que não se apresentam no discurso da proposta mais radical da Reforma Psiquiátrica, a da "desinstitucionalização como desconstrução".

Embora encontremos algumas proximidades nas concepções de alteridade presentes na desinstitucionalização como desconstrução, 
observamos que a radicalidade da proposta de Lévinas incita a uma transformação mais profunda, que não pretendemos esgotar, mas que nos leva a refletir sobre o percurso da inclusão da loucura.

O campo da Saúde Mental, relacionado ao processo de Reforma Psiquiátrica, opera privilegiadamente com a categoria de subjetividade, que apresenta diferentes concepções, dependendo das vertentes teóricas que a fundamentem. A perspectiva da alteridade no pensamento levinasiano possibilita uma reconfiguração na relação entre subjetividade e alteridade que pode contribuir para desencadear discussões teóricas fecundas sobre o tema, estimulando a capacidade de desalojamento, fundamental à reflexão.

\section{Referências}

AMARANTE, P. (Org.) O homem e a serpente: outras histórias para a loucura e a psiquiatria. Rio de Janeiro: Fiocruz, 1996.

. Loucos pela vida: a trajetória da reforma psiquiátrica no Brasil. Rio de Janeiro: Fiocruz, 1998.

COSTA, M. L. Lévinas: uma introdução. Petrópolis: Vozes, 2000.

FOUCAULT, M. História da loucura na idade clássica. São Paulo: Perspectiva, 1987.

FREIRE, J. C. O lugar do outro na modernidade tardia. São Paulo: Annablume, 2002.

LÉVINAS, E. Entre nós. Petrópolis: Vozes, 2005.

. Théorie de l'intuition dans la phenoménologie de Husserl. Paris: Vrin, 1963.

. Totalidad e infinito: ensayo sobre la exterioridad. Salamanca: Sígueme, 1977.

PITTA, A. (Org.). Reabilitação psicossocial no Brasil. São Paulo: Hucitec, 1996.

ROTELLI, F.; LEONARDIS, O.; MAURI, D. Desinstitucionalização. São Paulo: Hucitec, 2001. 
A Alteridade no Discurso da Reforma Psiquiátrica Brasileira...

SARACENO, B. Reabilitação psicossocial: uma estratégia para a passagem do milênio. In: PITTA, A. (Org.). Reabilitação psicossocial no Brasil. São Paulo: Hucitec, 1996. p. 13-18.

\section{NOTAS}

- Doutoranda em Ciências Médicas na Universidade Federal do Ceará/Médica Psiquiatra da Secretaria Municipal de Saúde de Fortaleza. Endereço Eletrônico: gabriela_godoy@uol.com.br.

- Professora Adjunta no Departamento de Saúde Comunitária da Universidade Federal do Ceará. Endereço Eletrônico: malubosi@ nesc.ufrj.br.

${ }^{1}$ Contratualidade é a capacidade de produção de valor social, a habilidade do individuo efetuar suas trocas simbólicas e materiais na família e no trabalho (SARACENO, 1996).

\section{ABSTRACT}

\section{Alterity in the Brazilian Psychiatric Reform Discourse in View of Lévinas's Radical Ethics}

This paper deals with some ethic premises of the Psychiatric Reform, more specifically, with desinstitutionalization as deconstruction, establishing a dialogue with the ideas of Emmanuel Lévinas. The concept of alterity is considered at the interface of radical ethic included in this approach. The discussion points out that the incorporation of ethical premises from the Psychiatric Reform can help understand the different possibilities and social consequences of this process, considering the diversity of practices being constructed and the growing of substitutive services in the Mental Health field.

Key words: Psychiatric Reform; alterity; mental health. 